\title{
The UN Special Rapporteur ON The Right to Health: A GUIDE FOR Civil Society
}

\author{
International Federation of Health and Human Rights Organisations, 2009, \\ Disponivel em <http://www.ifhhro.org/files/guide_2009.pdf>
}

\author{
Renata Reis(*) \\ Juana Kweitel(**)
}

\section{INTRODUÇÃO}

O sistema internacional de proteção dos direitos humanos somente funciona na medida em que as vítimas e as organizações da sociedade civil se apropriam dele. Neste sentido, a literatura coincide em destacar os mecanismos ou procedimentos especiais do Conselho de Direitos Humanos como uma das experiências melhor sucedidas do sistema internacional. Assim, os mecanismos especiais (relatores especiais por país e temáticos e os grupos de trabalho) têm sido considerados a jóia do sistema internacional de direitos humanos ${ }^{(1)}$.

Talvez por isso durante o processo de reforma do sistema, que se iniciou em 2005 e que culminou com a criação do novo Conselho de Direitos Humanos, os Estados mais interessados em enfraquecer a proteção dos direitos humanos atacaram insistentemente estes mecanismos.

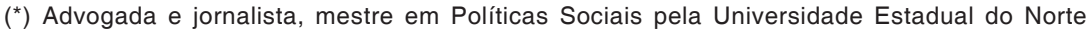
Fluminense Darcy Ribeiro - UENF / Universidade Livre de Bruxelas, Belgica, especialista em Propriedade Intelectual pela Fundação Getúlio Vargas - FGV, advogada da Associação Brasileira Interdisciplinar de AIDS (ABIA) e coordenadora do Grupo de Trabalho sobre Propriedade Intelectual (GTPI). E-mail: <renata@ abiaids.org.br>

$\left.{ }^{(* *}\right)$ Mestranda em Ciência Política na Universidade de São Paulo; pós-graduada em Direitos Humanos e Transição Democrática, pela Universidade do Chile, mestre em Direito Internacional dos Direitos Humanos pela Essex University, Reino Unido, advogada formada pela Universidade de Buenos Aires (UBA), coordenadora do Programa Sul Global da Conectas Direitos Humanos e editora associada da Sur - Revista Internacional de Direitos Humanos. E-mail: <Juana.kweitel@conectas.org>

(1) Para uma descrição geral do sistema não convencional de direitos humanos, ver: RODLEY, Nigel. United Nations Non-treaty Procedures for Dealing with Human Rights Violations. In: HANNUM, Hurst (Ed.). Guide to international human rights protection. New York: Transnational Publishers, 1999. p. 61-85. 
Felizmente, a reforma não acabou com os mecanismos especiais. $\mathrm{O}$ resultado da negociação foi a adoção de um Código de Conduta(2) que rege vários aspectos do trabalho dos relatores especiais e também uma importante modificação do sistema de eleição( ${ }^{(3)}$ de novos relatores, que proporciona mais transparência a este processo.

Neste contexto, o Guia resenhado tenta aproximar os potenciais usuários destes mecanismos a uma das relatorias em particular, aquela dedicada a proteção e promoção do direito à saúde.

\section{RELATORIA SOBRE O DIREITO À SAÚDE}

A expressão "procedimentos especiais" faz referência aos mecanismos estabelecidos pela antiga Comissão de Direitos Humanos e assumidos pelo Conselho de Direitos Humanos para enfrentar, situações concretas em países ou questões temáticas de direitos humanos no mundo inteiro. Atualmente existem 30 mandatos temáticos e 8 mandatos por país. O Escritório do Alto Comissariado para os Direitos Humanos das Nações Unidas presta apoio a estes mecanismos, facilitando recursos humanos, apoio logístico e a pesquisa necessária para seu desenvolvimento.

As resoluções que criam os mandatos dos procedimentos especiais pelo geral encomendam aos seus titulares examinar, supervisionar, assessorar e informar publicamente sobre as situações de direitos humanos em países ou territórios específicos ou em relação aos principais problemas de direitos humanos a nível mundial.

Os procedimentos podem ser realizados por uma pessoa (denominada Relator Especial, Representante Especial do Secretário Geral, Representante do Secretário Geral, ou Experto Independente) ou por um grupo de trabalho composto por cinco membros (um de cada região). Os responsáveis pelos mecanismos especiais desempenham sua função a título pessoal e não recebem remuneração ou contribuição financeira pelo trabalho(4).

A Relatoria sobre o Direito à Saúde foi criada por resolução da Comissão de Direitos Humanos em 2002, através de uma resolução originalmente proposta pelo Brasil. Em 2007 o mandato foi renovado pelo Conselho de Direitos Humanos.

(2) UNITED NATIONS HUMAN RIGHTS. Disponível em: <http://www2.ohchr.org/english/bodies/ chr/special/docs/CodeofConduct_SP.pdf>.

(3) Ver Conselho de Direitos Humanos. Resolução 5/1, 18 de junho de 2007. Disponível em: <http:/ lap.ohchr.org/documents/E/HRC/resolutions/A_HRC_RES_5_1.doc>.

(4) Ver site do Alto Comissariado para os Direitos Humanos. Disponível em: <http://www2.ohchr.org/ spanish/bodies/chr/special/index.htm>. 
Esta talvez seja uma das relatorias mais complexas de levar adiante, tanto pela diversidade de temas que engloba quanto pela pluralidade de atores e públicos com os quais se deve trabalhar. $\mathrm{O}$ antigo Relator, o professor Paul Hunt, teve a oportunidade de tratar assuntos tão diversos como mortalidade materna, acesso a medicamentos, e saúde mental; interagindo ao mesmo tempo com as vítimas, os agentes de saúde, o setor farmacêutico, e as organizações internacionais, como a Organização Mundial do Comércio, onde Paul Hunt, fez sua primeira missão.

\section{OBJETIVOS DO GUIA E DESCRIÇÃO DOS MÉTODOS DE TRABALHO}

Os objetivos do Guia são muito claros e atingidos ao longo do texto:

- Aumentar o grau de conhecimento sobre o trabalho do Relator Especial

- Ajudar às organizações da sociedade civil a se envolver mais no trabalho do Relator Especial, e

- Estimular a que as organizações da sociedade civil envolvam os agentes da saúde neste trabalho.

A principal virtude do Guia é conseguir sistematizar um trabalho que na verdade é marcado por um algo grau de discricionaridade. Assim, informa que o Relator:

- Realiza Relatórios Anuais

- Realiza visitas aos países

- Recebe denúncias individuais

Em março de 2009, o Relator realizou uma consulta com a sociedade civil de América do Sul, organizada em São Paulo por Conectas Direitos Humanos, ABIA (Associação Brasileira Interdisciplinar de AIDS) e SPW (Sexuality Policy Watch). Neste encontro, Dragana Korljan, assistente do Relator destacou algumas informações importantes para se ter em consideração ao encaminhar uma denúncia individual à Relatoria:

- Identificar o autor e a organização

- Informação de contato

- Sítio web

- Informar se o autor é membro de uma rede, e se sim, de qual

- O que dizer:

- Descrever as circunstâncias do incidente

- Indicar data e lugar 
- Informar os dados das vítimas (nome, sexo, origem, etc.)

- Informar se tem o consentimento da vítima para encaminhar o caso

- Se a vítima sabe e está de acordo do Relator

- A vítima deve saber que seu nome pode aparecer no relatório anual

- A vítima pode solicitar que seu nome não seja incluído, e que constem apenas suas iniciais

- Se é um grupo, incluir os dados de identificação

- Se possível, identificar os autores da violação

- Se possível, indicar se o incidente foi denunciado às autoridades e que medidas estas adotaram

- Fazer a relação entre o caso e o mandato para o qual encaminha a denúncia

- Incluir vários relatores se possível

- A informação deve ser:

- Clara

- Verossímil

- Consistente

- Sintética mas apoiada em documentos que possam ser solicitados posteriormente

Em determinadas circunstâncias os relatores podem também notificar à imprensa sobre determinada situação. Em alguns casos, vários relatores juntos realizam estas notas. Este instrumento permite dar visibilidade internacional para determinadas problemáticas. Em maio de 2009, por exemplo, quatro relatores especiais fizeram uma nota à imprensa sobre a situação no Sri Lanka. Nesta nota o Relator para o direito à saúde alertou sobre a falta de disponibilidade de medicamentos para a população civil atingida pela crise humanitária no país. Em 2004 e 2005, o Relator para o direito à saúde também chamou atenção para os governos do Peru e dos Estados Unidos que estavam negociando naquele momento um acordo bilateral de livre comércio. Ele destacou que as negociações poderiam colocar em risco as salvaguardas para o direito à saúde internacionalmente acordadas, causando o aumento dos preços dos medicamentos essenciais, tornando-os inacessíveis para milhões de peruanos ${ }^{(5)}$.

(5) Relator para o Direito à Saúde, Press release do 13 de julho de 2005, disponível no site do Alto Comissariado para os Direitos Humanos. 


\section{O NOVO RELATOR: ANAND GROVER}

Em 2008 o Conselho de Direitos Humanos, através do novo processo de eleição de relatores especiais, elegeu um novo Relator para o Direito à Saúde. Trata-se de Anand Grover, advogado indiano.

Anand Grover assumiu o cargo de Relator Especial da ONU em 1을 de agosto de 2008. Grover é também Diretor da organização Lawyers Collective na Índia, que tem escritórios em Mumbai, Nova Déli e Bangalore. Seu trabalho como advogado ajudou a impedir que o medicamento Nevirapina, destinado ao tratamento do HIV/AIDS, fosse patenteado no país, além de liderar diversas ações jurídicas e administrativas para impedir patenteamentos imerecidos de medicamentos essenciais na Índia.

Grover é um advogado militante que tem ocupado lugar de destaque em diversos casos de grande repercussão sobre questões de interesse público e direitos humanos, como aqueles relacionados ao meio ambiente, assédio sexual e direitos dos animais. Ele também tem atuado em casos sobre direitos ligados ao casamento entre pessoas do mesmo sexo e direitos de profissionais do sexo. Elaborou, a pedido do governo indiano e com o apoio do Departamento de HIV/AIDS da organização Lawyers Collective, um projeto de lei sobre HIV, que atualmente está em trâmite. Recentemente, Grover atuando como advogado de uma organização que trabalha contra a discriminação por orientação sexual logrou uma decisão histórica que declara inconstitucional a lei que criminaliza o sexo entre pessoas do mesmo sexo na Índia.

Durante o encontro organizado em São Paulo em março de 2009, Grover destacou que na sua visão, o contato direto com as comunidades afetadas pelas violações ao direito à saúde é essencial para garantir a consistência e a qualidade de seu trabalho como Relator Especial.

Também anunciou que ao longo de seu mandato espera abordar, entre outros, os seguintes temas:

- O alcance do consentimento no acesso a tratamento de saúde e o direito à informação (a fim de discutir o impacto negativo de tratamentos forçados);

- As conseqüências na saúde da criminalização de diferentes condutas como:

- Uso de drogas

- Trabalho sexual

- Transmissão de HIV

- O impacto da violência contra minorias sexuais e contra as mulheres 
Em relação à nossa região, o Relator solicitou que as organizações continuem encaminhando informação para ele de forma permanente, em particular sobre dois assuntos: direito a saúde dos povos indígenas e dos afro-descendentes.

\section{O PRIMEIRO RELATÓRIO DE ANAND GROVER PARA O CONSELHO DE DIREITOS HUMANOS}

O atual relator para a saúde apresentou seu primeiro relatório (documento ONU A/HRC/11/12) em fins de março de 2009 enfocando temas caros à saúde pública, em especial à assistência farmacêutica e ao acesso das populações aos medicamentos. O ponto de partida do relatório foi a relação entre o direito à saúde e as regras de propriedade intelectual, já que tais regras impactam diretamente os preços dos medicamentos e, por conseqüência, o acesso das populações, principalmente nos países mais pobres. É sabido que as regras de apropriação intelectual, com ênfase para as patentes de invenção, geram monopólios, limitam a competição e inibem a entrada de medicamentos genéricos no mercado. Tal situação não deve ser encarada como uma mera regra do âmbito comercial e deve ser avaliada do ponto de vista da saúde. É muito importante que o primeiro relatório do Anand Grover traga esse tema, colaborando para que esta situação não saia da agenda da Organização das Nações Unidas.

O enrijecimento das regras de propriedade intelectual, colocadas nos anos 90 pela Organização Mundial do Comércio (OMC), não encontrou seu apogeu na assinatura do Acordo TRIPs ${ }^{(6)}$. Embora o Acordo em questão já seja por si bastante rígido e amplo, o aprofundamento das regras em países em desenvolvimento continua a ocorrer, principalmente através de acordos de comércio que seguem incluindo capítulos de propriedade intelectual. Além disso, há questões que o relatório traz e que podemos considerar que estão "sob um véu de esquecimento" por parte dos organismos internacionais multilaterais, como por exemplo a não incorporação de flexibilidades de interesse para a saúde pública, permitidas por TRIPs nos países em desenvolvimento e LDCs.

Entre as flexibilidades não incorporadas o relator traz pontos fundamentais para o debate: períodos de transição para incorporação de TRIPs nas leis nacionais dos países; definição de critérios de patenteabilidade baseado nos mais altos padrões (impedindo a concessão de patentes imerecidas de medicamentos e insumos de saúde); possibilidade de emissão desburocratizada de licenças compulsórias e licenças de uso governamental não comercial; criação de limitações aos direitos de patente tendo por princípio o interesse público, entre outras medidas.

(6) Agreement on Trade-Related Aspects of Intellectual Property Rights (TRIPs). 
Outro ponto muito importante trazido pelo relator são os aprofundamentos das regras de propriedade intelectual com base em acordos de comércio diversos, como os Tratados Bilaterais de Investimento (BITs), Acordos de Livre Comércio (FTAs), Acordos de Parcerias Econômicas (EPAs), etc. Tais acordos, sob os auspícios das pastas de comércio e relações exteriores dos países terminam por tratar de temas muito sensíveis ao acesso das populações a medicamentos essenciais. Não é raro que constem nas mesas de negociações de tais acordos restrições ou a supressão das flexibilidades do Acordo TRIPs, como por exemplo a extensão dos prazos de vigência de patentes e a ligação forçada entre patentes e registro sanitário de medicamentos nos países, fazendo com que a comercialização dos mesmos tenha vinculação direta com a concessão de monopólio de exploração através de uma carta patente.

O relatório tem o mérito de trazer pontos chave para o debate do acesso a tratamentos e as práticas monopolistas que são um forte obstáculo para o acesso, entre eles pontos novos no cenário, como o avanço dos debates sobre o Acordo anti-contrafação $(A C T A)^{(7)}$, cujo tema tem levantado uma série de críticas por parte de organizações da sociedade civil, na medida em que podem significar mais uma barreira aos medicamentos genéricos, e o reforço da criminalização das infrações de patentes. As recomendações do relator nos parecem trazer o coração dos atuais problemas e recomendamos fortemente um esforço geral dos governos e organismos internacionais para que sejam implementadas.

\section{COMO CONTRIBUIR COM O RELATOR ESPECIAL?}

O Guia traz uma convocação concreta com a qual concordamos inteiramente. Para que este mecanismo funcione faz-se necessário uma ampla divulgação. É importante que as organizações e as vítimas de violações conheçam os relatórios. Para tanto, são fundamentais os esforços para que os mesmos sejam traduzidos para as línguas locais. Os relatórios devem inclusive ser criticados pelas organizações que trabalham em cada um dos temas. A análise crítica e construtiva dos relatórios por organizações da sociedade civil é também uma forma de contribuir com o trabalho da Relatoria.

Nota das autoras: Os interessados podem solicitar cópias do Guia para a.m.dibbets@uu.nl. Na mensagem devem indicar o endereço para o qual querem receber as cópias do documento, quantidade desejada e detalhar como o Guia será utilizado.

(7) Anti-Counterfeiting Trade Agreement. 


\section{REFERÊNCIAS BIBLIOGRÁFICAS}

ALTO Comissariado para os Direitos Humanos. Disponível em: <http:// www2.ohchr.org/spanish/bodies/chr/special/index.htm>.

CONSELHO DE DIREITOS HUMANOS. Resolução 5/1, 18 de junho de 2007. Disponível em: <http://ap.ohchr.org/documents/E/HRC/resolutions/ A_HRC_RES_5_1.doc>.

RODLEY, Nigel. United Nations Non-treaty Procedures for Dealing with Human Rights Violations. In: HANNUM, Hurst (Ed.). Guide to international human rights protection. New York: Transnational Publishers, 1999. p. 61-85.

UNITED NATIONS HUMAN RIGHTS. Disponível em: <http://www2.ohchr.org/ english/bodies/chr/special/docs/CodeofConduct_SP.pdf>. 